\title{
Modelling of Thin Structural Polymer Composites for Use of Automobiles -Review-
}

\author{
Daisuke Narita, ${ }^{\text {a* }}$ Yoshihiro Narita, ${ }^{\mathrm{b}}$ \\ ${ }^{a}$ Hokkaido University of Science Junior College, Teineku, Sapporo, Japan. Email: narita@ hus.ac.jp \\ ${ }^{b}$ Hokkaido University, C-BEST, Center of Technology, Faculty of Engineering, University of Hasanuddin, South Sulawesi, Indonesia. \\ Email: ynarita@eng.hokudai.ac.jp
}

\begin{abstract}
This review article introduces first a number of previous works and commercial examples on the use of fiber-reinforced polymer materials in the application to automobile structural components, and secondly considers the modeling for thin components of fiber-reinforced polymer composites with emphasis on the roofs and fenders of the automobiles. The need of this study seems obvious, since particularly in the sportive and high-grade automobiles, the composite materials have already replaced conventional metal materials resulting in the significant reduction of structural weight. In such application, laminated composite panels (shallow shells) are used for models of automotive panels. The structural components in the automobile are extensively exposed to vibration excitation and other external disturbances in practical use, and resonance phenomenon may cause disturbing effects such as noise and fatigue. One countermeasure for such negative effects is to make use of tailoring advantages for fiber reinforced laminated composites and the feasibility for optimization process is suggested.
\end{abstract}

Keywords: Automotive application; composite material; mechanical engineering; modeling; review

\section{Introduction}

Advanced composite materials are generally made of two or more material elements, namely fibers such as carbon or glass fibers, and matrix materials of thermoset or thermoplastic polymers. Particularly, carbon fiber is a flexible fabric-like soft material, but it has high strength and stiffness when it is under tension, almost equivalent to metal of equal size. The fiber is therefore used to act as reinforcing element in the base matrix material. Advantage of using polymer as the matrix material is that it can be molded into the shape of various parts that are stronger and lighter than today's steel and aluminum parts. For making a relatively large structural component with several different parts integrated, molding capability of the polymer composites become dominant by using the integrated molding.

The problem in using fiber-reinforced, polymer-based material for general industrial products is the high cost due to the high cost of fiber material itself, and therefore the use of composites has started mainly in less cost-sensitive aerospace and aeronautical industries. Another drawback is

\footnotetext{
${ }^{*}$ Corresponding author. Tel.: +81-11-706-6415

Kita-13, Nishi-8, Kita-ku

Sapporo, Hokkaido, Japan, 060-8628
}

to take longer production time due to molding and curing time, while metal thin parts are usually stamped in the order of seconds. In the present article, the use of polymer composite material reinforced by carbon fibers is considered in structural components of automobiles. The past progress is summarized through literature survey and practical applications found in commercial automobiles, and the analytical and numerical modeling approaches are presented for modeling of thin panels used in the automobile structure.

\section{Literature review on application of composites in automobiles}

When fiber-reinforced polymer composites are used in the structure of automobiles, they can yield significant reduction of vehicle weight due to their high strength-toweight and stiffness-to-weight ratios. Many efforts of research and development have been done in the past few decades.

Das [1] examined the cost of automotive polymer composites in 2001 for the first time and assessed Doe Chemical's efforts to develop light weight materials in the automotive applications. This work addressed the use of composites extensively in automotive application, the unsolved issues for expanding the use, and the needs of 
research for such challenges. As the title implied, the main focus was placed on studying the economic viability of these materials two decades ago. Some years later, a roadmap for future use of plastics and composites was shown [2] in 2007 for the safety of highly intensive automobiles. This work reported the approaches, activities and outcomes of the research to study advantages from the safety viewpoints of composites-intensive cars. The purpose of this report was therefore to review and examine the state of knowledge to identify the gaps, key research needs and potentials for safety enhancement.

In the year of 2012, two review papers were published. Andure and others [3] summarized basic knowledge of structural properties, mechanical properties and application examples of various type composites in automobiles. Mahajan and Aher [4] presented design method and vibration analysis of composite propeller shaft to discuss the advantage of replacing metal shaft with composite shaft. Rathnakar and Pandian [5] presented a comprehensive review on the use of polymer composites in automotive industry, and emphasized the promising technical possibilities for fabricating more automotive components with fiber composites. They concluded that the cost acts as the final arbitrator in the selection of particular composite material for a specific application. More recently, Pervaiz and others [6] reviewed situations of the main motives and current legislation, when the original equipment manufacturers (OEM) for automotive industries face for weight reduction. They also studied emerging effects in development of light-weighting materials on low-cost carbon economy. The most recent survey work was made by Masilamani and others [7] and they discussed in detail with the benefits of usage of carbon-fiber reinforced plastics (CFRP) in each part of car, i.e., bumper, hood or bonnet, roof and so on.

The review articles mentioned above dealt mostly with use of polymer composite materials with chemical fibers made from petroleum resource. From viewpoint of sustainability in natural resource, however, bio-composites (green-composites) may play more important role than before, and such materials deriving from renewable resources will be preferred as opposed to the exhaustible fossil products. Koronis and others [8] provided in 2013 a literature review in the broad field of bio (green) composites seeking for practical materials with a potential to be applied in the new future on automotive body panels. The literature [9] also provided in 2017 an overview of bio-composites application in the automotive, including the history and progressive steps that were taken to break into the production lines of some car-makers. This also offered an analysis of key factors that have motivated the research and practical adoption of bio-composites. The recent review by Fagorasi and Barbu [10] in 2017 considered a wide range of bio-composites issues with special reference to mechanical properties of fibers, interfacial adhesion and environmental implication.
The bumper, one of automotive structural elements, may be one of the most frequently applied targets of the advanced composites, since it contributes to vehicle crashworthiness and occupant protection at the time of front or rear collisions. Sapuan and others [11] presented a first review of polymerbased composite bumper system in 2002, and discussed proper bumper design, material selection and manufacturing process. After more than ten years in 2014, John and Alex [12] summarized the progress in various studies about the selection of composite materials for desirable production of bumpers. They specifically considered energy absorption, performance, cost, weight, service conditions, manufacturing process, availability of materials, and environment aspects. Similarly, Ezekwem [13] took up this problem by comparing two types of bumpers made from nylon composites and polyethylene with specific fillings. The mechanical properties of these materials showed superior characteristics on weight, cost and environment impact than conventional bumper, except for difficulty in mass production.

As compared to active research on bumper, analytical studies on mechanical design and material selection are limited on application of thin composites to bonnet and roof structure. They have been used in expensive automobiles such as sportive cars, and on-going examples are introduced in the next chapter. One of sparse literatures is the study on analysis and design of thermoplastic CFRP bonnet for pedestrian safety [14]. This study is one of the examples in the efforts to follow Japanese standard for pedestrian protection [15].

\section{Practical examples in application of composites for automobiles}

In recent years, the application of fiber reinforced polymer composite materials is expanding to not only to aeronautical and astronautical fields but also to commercial expensive vehicles. Such examples are found in the monocoque bodies of expensive sports cars as shown in Fig.1 and 2 for McLaren Automotive 720S [16] and Lamborghini Aventador [17], respectively. For thin panel structural components, such as bonnet and roof, some applications are seen for outer-surface panels in Fig.3 and Fig.4 for Lexus RCF [18] and Subaru WRXSTIS [19], respectively. These are not as considerably expensive as those shown in Fig. 1 and 2, but still belong to a class of luxurious cars. For inner-surface of bonnet and fender, the composites are already used for the panels where stiffening parts are included additionally. Those examples are seen in inner-surface of bonnet for Nissan GT- R in Fig. 5 [20] and in Fig. 6 for Toyota Prius [21]. In contrast to the applications above [16-21] to relatively thin panels, CFRP

CFRP composites have been used in large production scale since in 1990's as propeller shafts, as shown in Fig. 7, to transmit torque from engine to wheels. The use for the propeller shafts brings significant effects on reduction of 
vehicle weight by the design where no intermediate supports are necessary and the absorption of dynamic energy is made possible at the collision situation.

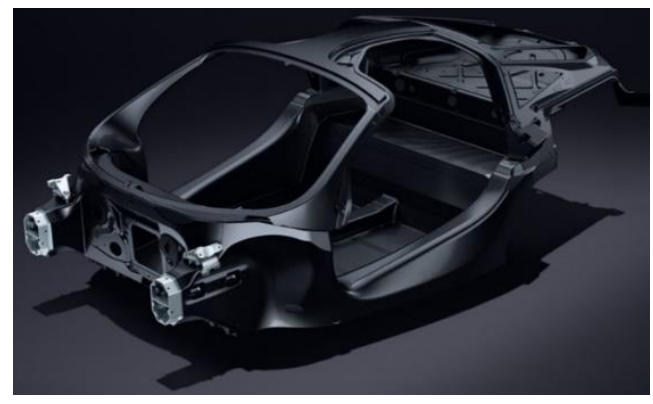

Figure 1. Monocoque body of Maclaren720S, [16].

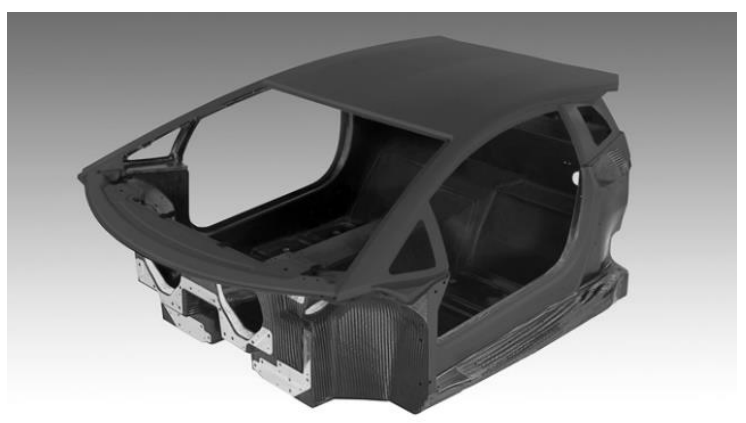

Figure 2. Monocoque body of Lamborghini Aventador, [17]

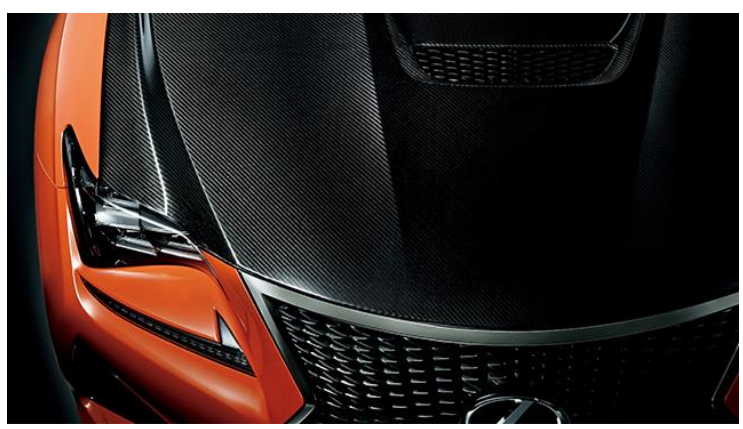

Figure 3. Bonnet (outer surface) of Lexus RC F Carbon Exterior package, [18]

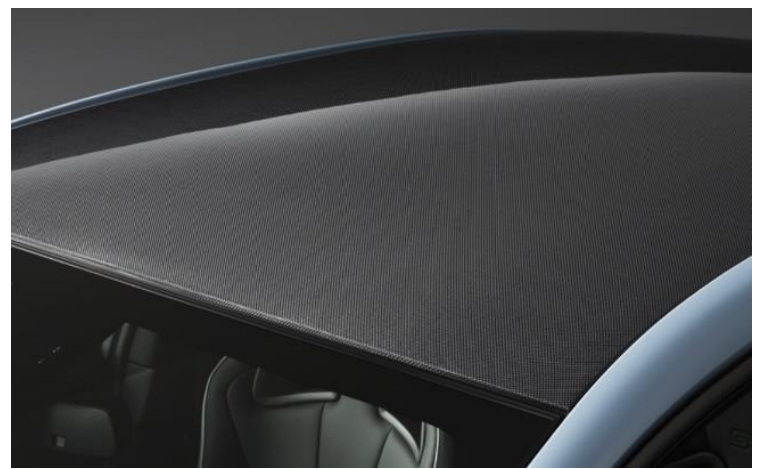

Figure 4. Bonnet (outer surface) of Subaru WRX STI S208 NBR, [19]

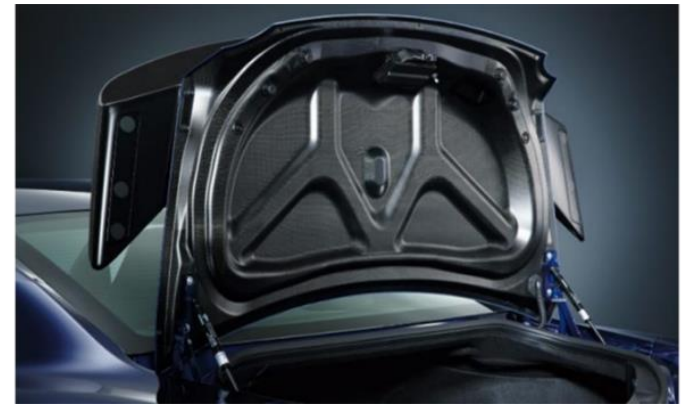

Figure 5. Bonnet (inner surface) of Nissan GT-R black edition, [20]

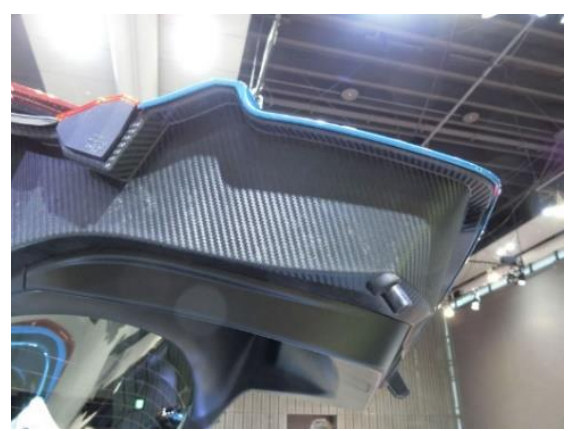

Figure 6. Bonnet (inner surface) of Toyota Purius PHV, [21]

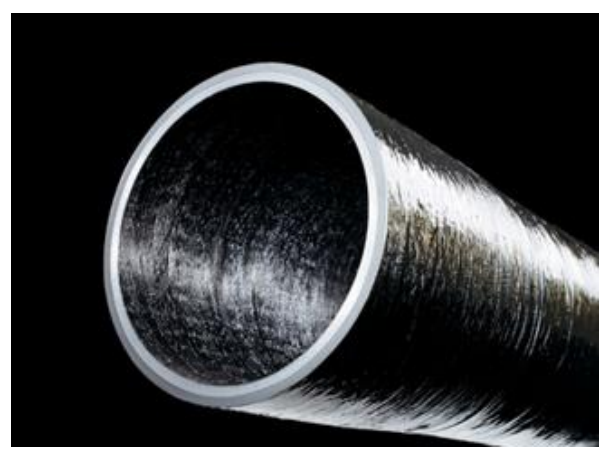

Figure 7. Example of a propeller shaft made of CFRP material, [22]

In Europe, the nation-wide scale project started in 2000's under the title of TECABS (Technologies for Carbon fiber reinforced modular Automotive Body Structures). This project consisted of Volkswagen, Daimler Chrysler, material manufacturers and research institutes to develop lightweight cars and to improve fuel efficiency. Also in Japan, NEDO (New Energy and Industrial Technology Development Organization) started a nation-wide project titled "Research project for development of carbon-fiber reinforced composite material for reduction of automobile weight", and one of the outcomes was success in the fast production process of the combined structure of front-floor and front side member. Besides these works, recently one of production methods "RTM (Resin Transfer Molding)" has been successfully developed, and lower cost became possible to fabricate automotive structures, for example, a body of electric cars BMWi shown in Fig. 8. 


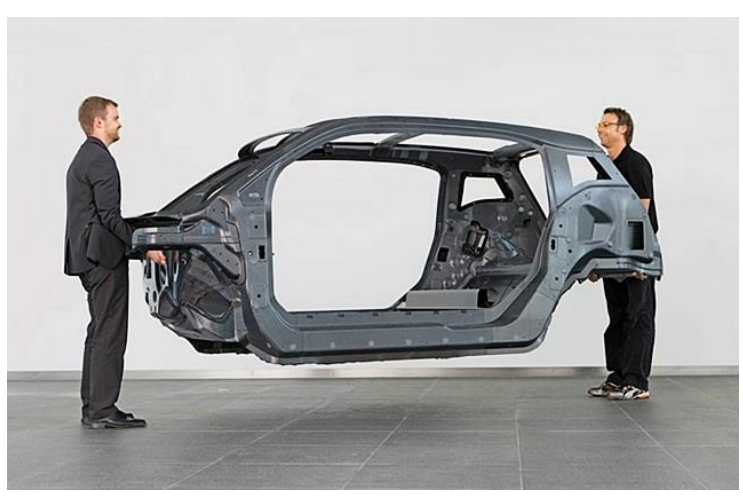

Figure 8. Monocoque body of BMW i3, [23]

Next, some new regulation is explained here in connection to the bonnet design in Japan. This regulation introduced a new concept to protect heads of pedestrians encountered in traffic accidents, because the rate of serious injuries of pedestrians involved in accident is very high and most of them suffer heavy head injuries. For this problem, the design of bonnets and front surfaces is considered to mitigate the impact between bonnets and pedestrian heads. The impact is measured by assuming the case when the head model is hit against the car front in $40 \mathrm{~km} / \mathrm{h}$, as shown in Figs. 9 and 10 . Some proposed counter-measures for design against impact include to unify the bending stiffness of bonnet, to set margins of movable range of bonnet and to keep distance to the hard part in the engine room, and also to design fenders being flexible enough.

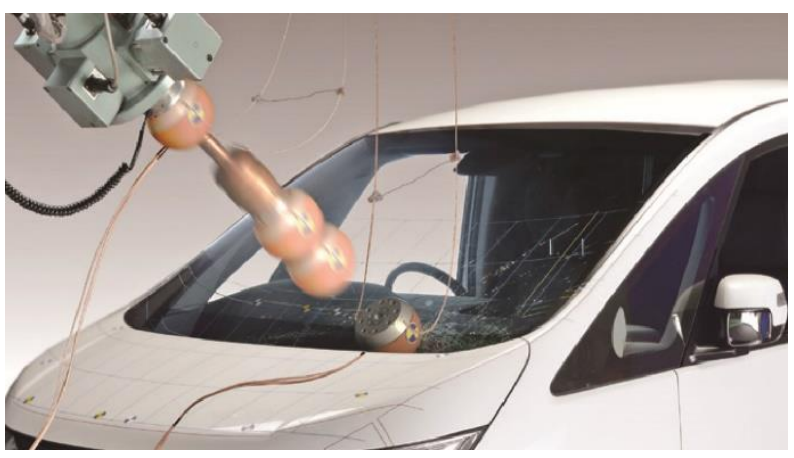

Figure 9. Impact test for assumption of pedestrian head, [14]

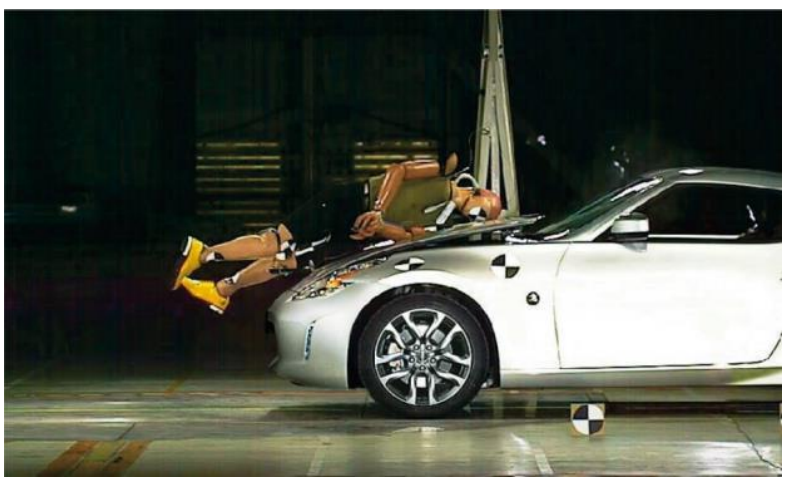

Figure 10. Collision test for assumption of a pedestrian, [23]
As previously mentioned, some examples already existed in application of CFRP composites to bonnet, their objectives are mostly for total weight reduction of the body, together with the function of energy absorption and global bending deformation not to break into the driver room at the time of collision. Kin and others [14] presented design of the bonnet made of CFTRP (carbon fiber thermoplastic plastics) to increase safety of pedestrians. The finite element analysis was made to follow the regulation for pedestrian safety, and the results showed that their designed CFTRP bonnet takes longer time to accept the impact, resulting in smaller damage to pedestrians' heads.

\section{Modeling approaches to bonnet and roof of automobiles}

This chapter overviews different modelling approaches to analyzed dynamic behaviors of thin panel structures. Some advantages and disadvantages of the approaches are summarized. The experimental modeling approach, such as the modal analysis technique [24], is not included in this work.

\subsection{Analytical model of automobile panels}

As shown in Fig.11, automobile panels may be modeled as shallow shell structure with non-uniform curvature. For this model, some works have been done by the present authors [25-30]. The dimension of the shell is assumed to be $a \times b$ as rectangular planform, and its $\mathrm{z}$-coordinate $\varphi$ measured from the mid-plane is defined by a cubic polynomial function of $x$ and $y$ in the coordinates shown in Fig.11, where $\mathrm{c}_{\mathrm{ij}}(i, j=0,1,2,3)$ are shape coefficients to determine shell shapes, and they may be determined by the least square method to match with actual shell shapes of automobile panels.

$$
\begin{gathered}
\phi(x, y)=c_{00}+c_{10} x+c_{01} y+c_{20} x^{2}+c_{11} x y+c_{02} y^{2} \\
+c_{30} x^{3}+c_{21} x^{2} y+c_{12} x y^{2}+c_{03} y^{3}
\end{gathered}
$$

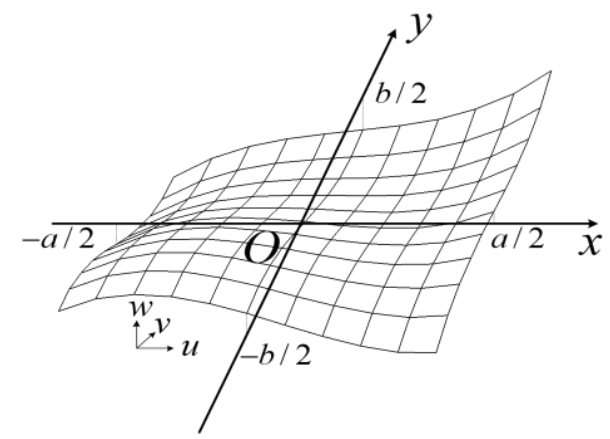

Figure 11. Coordinate system for analysis of doubly curved panel 

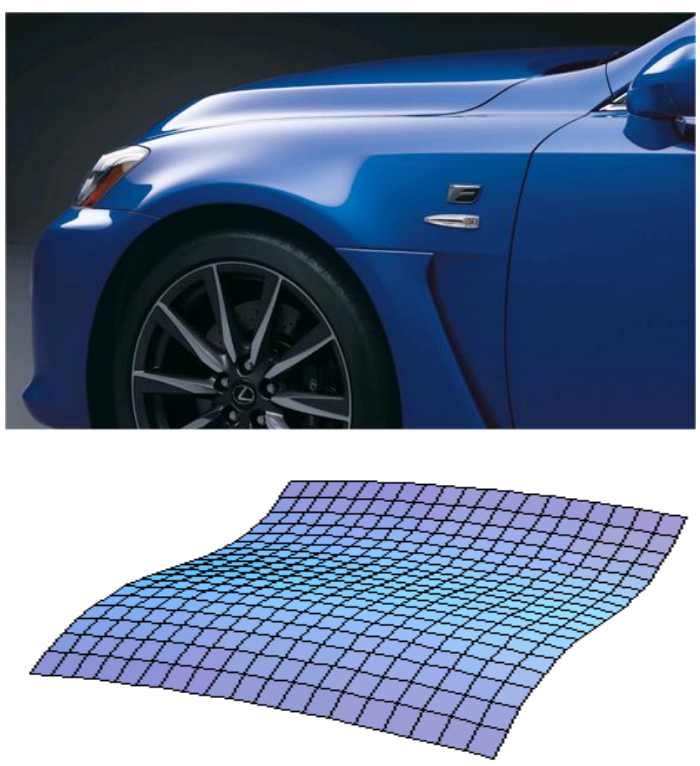

Figure 12. Fender models represented by a cubic function,

(a) $\phi(x, y)=-0.1 x^{2}+y^{3}$
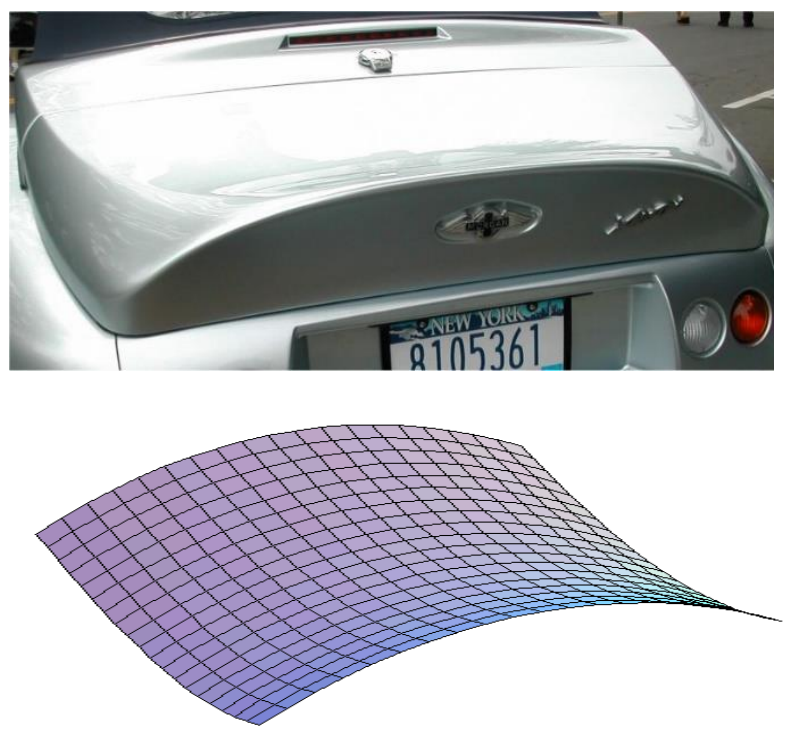

Figure 12. (b) $\phi(x, y)=0.5 x^{2}-y^{2}+0.5 x^{2} y$

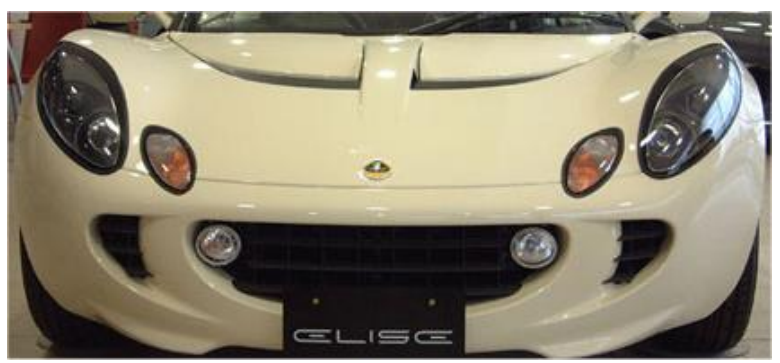

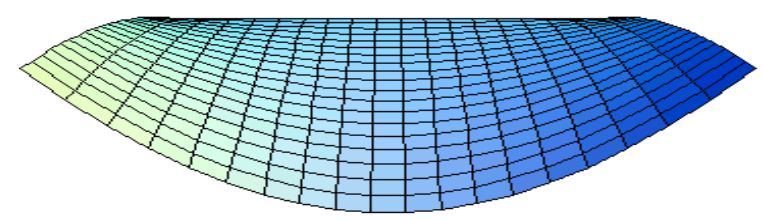

Figure 12. (c) $\quad \phi(x, y)=0.5 x^{2}-0.1 y^{2}-x^{2} y$
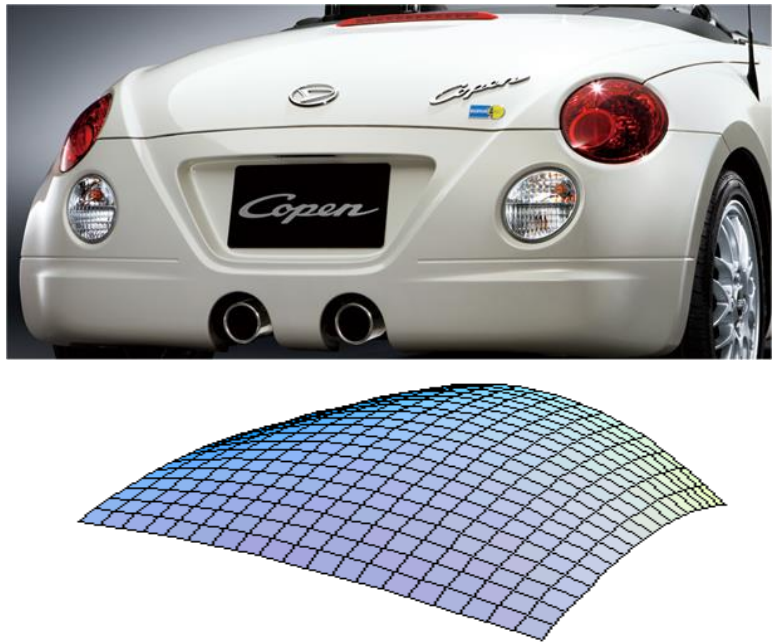

Figure 12. (d) $\phi(x, y)=-x^{2}-0.6 y^{2}-1.5 x^{2} y$

Four examples are presented in Fig. 11 to demonstrate the effectiveness of the present analytical model in practical situations. Fig. 12(a) is an example of a shell panel shape with both convex and concave curvature existing in one region and it is represented by $\phi(x, y)=-0.1 x^{2}+y^{3}$.

Figures 12(b)(c) and (d) are cases with only concave or convex curvature existing in the region, represented by the equations written in the figure captions.

Based on the Donnel-Mushtari theory, relation between displacements $u, v$ and $w$ and strains $\varepsilon_{x}, \varepsilon_{y}$ and $\gamma_{x y}$ is defined by

$$
\begin{aligned}
& \varepsilon_{x}=\frac{\partial u}{\partial x}+\frac{w}{R_{x}}, \varepsilon_{y}=\frac{\partial v}{\partial y}+\frac{w}{R_{y}}, \\
& \gamma_{x y}=\frac{\partial v}{\partial x}+\frac{\partial u}{\partial y}+\frac{2 w}{R_{x y}}
\end{aligned}
$$

In the Ritz method, vibration of composite shells with non-uniform curvatures may be analyzed, and the method is useful for the parametric study in varying boundary conditions, aspect ratios and shell shapes.

The Ritz method is a kind of energy method, and it evaluates strain and kinetic energies to derive mechanical responses, for example, natural frequencies. The strain energy is given by

$$
U=U_{s}+U_{b s}+U_{b}
$$

where $U_{s}, U_{b s}$ and $U_{b}$ are the energy due to in-plane deformation, coupling between in-plane and out-of-plane 
and out-of-plane deformation, respectively, and they are given by

$$
\begin{aligned}
& U_{b}=\frac{1}{2} \iint\{\varepsilon\}^{T}[A]\{\varepsilon\} d x d y, \\
& U_{b s}=\frac{1}{2} \iint\left(\{\kappa\}^{T}[B]\{\varepsilon\}+\{\varepsilon\}^{T}[B]\{\kappa\}\right) d x d y, \\
& U_{b}=\frac{1}{2} \iint\{\kappa\}^{T}[D]\{\kappa\} d x d y
\end{aligned}
$$

where $\{\varepsilon\}$ is the strain vector and $\{\kappa\}$ is the curvature vector in the plate mid-plane. Matrixes $[A],[B]$ and $[D]$ are stiffness matrixes [31-33] of extension, extension-bending coupling and bending, respectively. The kinetic energy is given by

$$
T=\frac{\rho h}{2} \iint\left[\left(\frac{\partial u}{\partial t}\right)^{2}+\left(\frac{\partial v}{\partial t}\right)^{2}+\left(\frac{\partial w}{\partial t}\right)^{2}\right] d x d y
$$

where $\rho$ is the mass density and $h$ is the thickness.

To make the analysis simple, non-dimensional coordinates $\xi=2 x / a$ and $\eta=2 y / b$ are introduced to above equations. Then, the displacement $u$ in the $x$ direction is defined by

$$
u(\xi, \eta, t)=\sum_{i=0}^{I-1} \sum_{j=0}^{J-1} P_{i j} X_{i}(\xi) Y_{j}(\eta) \sin \omega t
$$

where $P_{i j}$ are unknown coefficients, and $X_{i}(\xi)$ and $Y_{j}(\eta)$ are functions that satisfy the geometric boundary conditions at each edge of the shell. They are defined by

$$
\begin{aligned}
& X_{i}(\xi)=\xi^{i}(1-\xi)^{B C 11}(1+\xi)^{B C 31}, \\
& Y_{j}(\eta)=\eta^{j}(1-\eta)^{B C 21}(1+\eta)^{B C 41}
\end{aligned}
$$

where $B C_{p q}(p=1,2,3$ and $4, q=1,2$ and 3) are boundary indexes. The subscript $p$ denotes each edge of the shell in counterclockwise direction from left edge of the shell, and $q$ is the degree-of-freedom to be constrained. The numbers 1 , 2 , and 3 means $u, v$ and $w$. The indices $B C_{p q}=0$ and 1 indicates free and simply supported edges for $q=1$ and 2, and $B C_{p q}=2$ indicates clamped edges for $q=3$. Displacements $v$ and $w$ are defined in the similar way with Eqs. (6) and (7). The functional $F$ defined by the difference of maximum strain energy $U_{\max }$ and maximum kinetic energy $T_{\max }$ is minimized with respect to unknown coefficients $P_{i j}, Q_{k l}$ and $R_{m n}$, and then frequency equation is derived to be solved numerically.

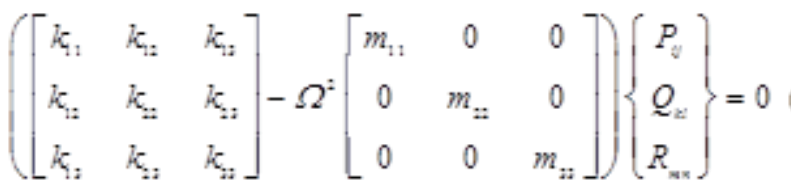

\subsection{FEM models of automobile panels}

The analytical models introduced in section 4.1 are computationally very efficient, but they have some limitations on the geometric expression. For more accurate geometric modeling, the use of the finite element method (FEM) is more suitable. Particularly, sophisticated modeling technology is available in commercial FEM software [3435].

Figure 13 shows the modeling process of thin composite structural part of automobile panel. In the modeling, first, a few lines are modeled as a basis. The first idea was to model simple areas and to realize area fillet between them to give the curved shape of the hood. This appeared quickly uneasy with ANSYS commands. Therefore, some key-points were placed on the skeleton to model lines all along the surface of the hood. Line fillets allowed modeling the curvature of the panel. The area was then created by skinning.

Similarly, Figure 14 shows a fender part panel of the hood, where dimensions are approximated with respect for the proportions but are inspired from real technical data. Also shown here in this figure are examples of accurate shape modeling in the FEM code. Similarly, in the preprocessor, key-points are chosen on the skeleton and set model lines all along the surface. Line fillets allowed modeling the curvature of the panel. The area was then created by skinning to derive the mesh. The design here is lead by using ANSYS, with Element Shell99 [36].
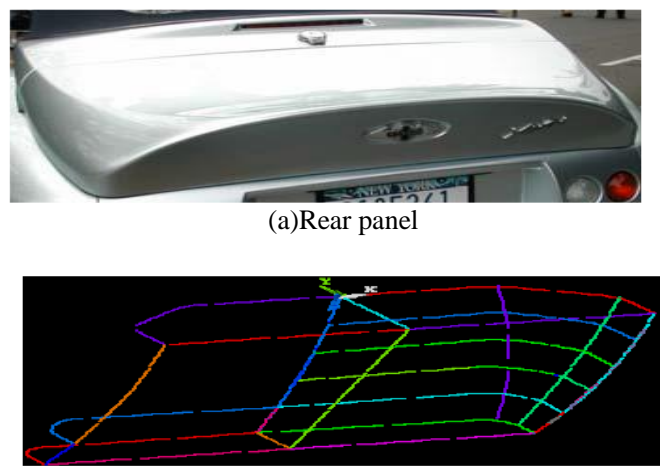

(b) Skelton model by using keypoint and surface

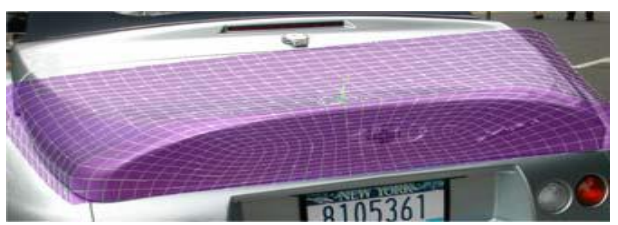

(c) Meshed model

Figure 13. Modeling process of a rear panel.

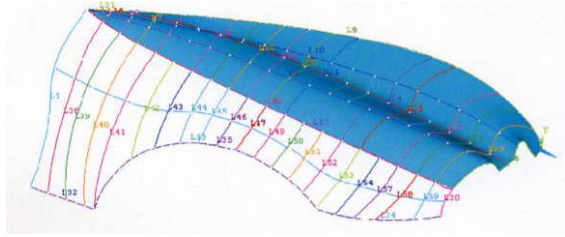

Example (a) 


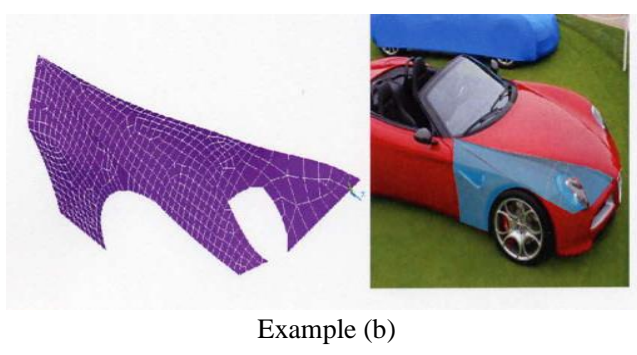

Figure 14. FEM modeling of fender

\section{Conclusions}

The present review-type work made efforts to cover the recent development found in the literature and to introduce practical applications in the last decade. Some other approach for pedestrian safety in Japan was also given. The application of fiber polymer composites, most likely CFRP, is promising in automotive industries worldwide, since the materials provide with higher specific strength/stiffness ratios and also the energy absorbing capability. The recent research also covers quality control of the materials, and efficient molding strategy. The cost, however, still acts as a decisive player in further extensive use of the material. As for thin panel modeling, two approaches are introduced here, one based on the cubic expression of curved surfaces, and the other more flexible surface shape modeler, that is the use of commercial finite element analysis code. The former has a limit in shape presentation, but the computation time is very short, therefore giving wider usability for timeconsuming computation, ie., optimum design of the composite panels for automobile bonnets and roofs. Finally, it is important to consider the optimization in the design process, but due to space limitation here, the topic will be presented in the next work.

\section{References}

[1] Das, S., The cost of automotive polymer composites: a review and assessment of Doe's lightweight materials composites research., US Department of Energy, 2001, ORNL/TM-2000/283.

[2] Brecher, A, A safety roadmap for future plastics and composites intensive vehicles, U.S. Department of Transportation, DOT HS 810863, 2007, www.nhtsa.gov.

[3] Andure, M.W., Jirapure, S.C., Dhamande, L.P., Advance automobile material for light weight future-a review, International Conference on Benchmarks in Engineering Science and Technology, Proceedings IJCA, 2012, pp.15-21.

[4] Mahajan, G.V., Aher, V.S., Composite material: a review over current development and automotive application, International Journal of Scientific and Research Publications, 2, 2012, pp.1-5.

[5] Rathnakar, G., Pandian, P., A review on the use and application of polymer composites in automotive industries, International Journal for Research in Applied Science \& Engineering Technology, 3, 2015, pp.898-903.
[6] Pervaiz, M., Panthapulakkal, S., Birat, K.C., Sain, M., Tjong, J., Emerging trends in automotive lightweighting through novel composite materials, Materials Sciences and Applications, 7, 2016, pp.26-38.

[7] Masilamani, R., Dhandapani, N.V., Kumar, K.V., Mani, K.T., A review on usage of carbon fiber reinforced plastics in automobiles, International Journal of Pure and Applied Mathematics, 117, 2017, pp.537-544.

[8] Koronis, G., Silva A., Fontul M., A review of adequate materials for automotive applications, Composites Part.B., 44, 2013, pp.120-127.

[9] Akampumuza, O., Wambua, P.M., Ahmed, A., Li, W., Qin, X., Review of the applications of biocomposites in the automotive industry, Polymer Composites, 38, 2017, pp.2553-2569.

[10] Fogorasi, M.S., Barbu, I., The potential of natural fibres for automotive sector -review-, IOP Conference Series: Materials Science and Engineering, 252, 2017, pp.1-11.

[11] Sapuan, S.M., Suddin, N., Maleque, M.A., A critical review of polymer-based composite automotive bumper systems, Engineering Review, 10, 2002, pp.627-628.

[12] John A., Alex, S., A review on the composite materials used for automotive bumper in passenger vehicle, International Journal of Engineering and Management Research, 4, 20144, pp.98-101.

[13] Ezekwem, L., Composite materials literature review for car bumper, ReserachGate, https://www.researchgate. net/publication/305775906, pp.1-11.

[14] Kin, T., Koyama, H., Uzawa, K., Takahashi, J., Morit, A., Structural optimization of CFRTP bonnet for pedestrian safety (in Japanese), 34th Symposium of Japan Society of Composite Materials, 2009, pp.135136 , ResearchGate, https://www.researchgate.net/publication/283087938

[15] National Agency for Automotive Safety \& Victim's Aid, Pedestrian head protection performance tests, http://www.nasva.go.jp/mamoru/en/assessment_car/head_protection_t est.html.

[16] Maclaren720S, referred from http://jp.cars. mclaren.com/

[17] Lamborghin Aventador, referred from http://www. lamborghini.com/

[18] Lexus RC F, Carbon Exterior package, referred from http://lexus.jp/

[19] Subaru WRX STI S208 NBR Challenge Package, referred from http://www.honda.co.jp/

[20] Nissan GT-R black edition, Track edition engineered by nismo, referred from http://www.nissan.co.jp/

[21] Toyota Purius PHV, referred from http://monoist. atmarkit.co.jp/

[22] CFRP propeller shaft, referred from http://nissan. co.jp/

[23] BMW i3, referred from https://clicccar.com/

[24] Bruel \& Kjar, Structural testing, part.2 modal analysis and simulation, 1988, https://www.bksv.com/ media/doc/br0507.pdf.

[25] Narita, D., Narita, Y., Vibration analysis of laminated shallow shells with non-uniform curvature (in Japanese), Transaction of JSME, 72, 2006, pp.3743-3750.

[26] Narita, D., Narita, Y., Vibration optimization of laminated shallow shells with non-uniform curvature, $16^{\text {th }}$ Proceedings of International Conference on Composite Materials, 2007, pp.1-8.

[27] Narita, D., Narita, Y., Analysis for vibration of laminated shallow shells with non-uniform curvature, Key Engineering Materials, Vol.334-335, (2007), pp.85-88. 
[28] Narita, D., Narita, Y., Analysis and design of curved laminated composite panels under external pressure, Key Engineering Materials, 353-358, 2007, pp.1271-1274.

[29] Narita, D., Narita, Y., Vibration analysis of shallow shells with general surfaces expressed by cubic polynomial function, Journal of System Design and Dynamics, 2, 2008, pp.105-116.

[30] Honda, S., Kato, T., Narita, Y., Narita, D., Multidisciplinary design optimization of surface shapes and lay-up configurations for composite laminated shells (in Japanese), Transaction of JSME, 77, 2011, pp. 1793-1802

[31] Vinson, J.R., Sierakowski, R.L., The Behavior of Structures Composed of Composite Materials, Martinus Nijhoff, Dordrecht, 1986.
[32] Reddy, J.N., Mechanics of laminated composite plates theory and analysis, CRC Press, Inc., 1997.

[33] Jones, R.M., Mechanics of Composite Materials, 2nd ed., Taylor \& Francis, 1999

[34] Couppie, C., Honda, S., Narita, Y., Layerwise optimization for vibration of automobile panels, Proceedings of The First Japan-Korea Joint Symposium on Dynamics and Control, 2009, pp.37-38.

[35] Narita, Y., Honda, S., Couppie, C., Layerwise optimization for vibration of automobile composite panels, Proceedings of 17 th International Congress on Sound and Vibration, 2010, (CD-ROM), pp.1-6.

[36] SHELL99, http://www.ansys.stuba.sk/html/elem_55 /chapter4/ES499.htm. 